\title{
ON THE OSCILLATION CERTAIN FOURTH ORDER NONLINEAR DYNAMIC EQUATIONS WITH A NONLINEAR MIDDLE TERM
}

\author{
SAID R. GRACE AND TAHER S. HASSAN
}

Abstract. New oscillation criteria for certain fourth order nonlinear dynamic equations with nonlinear middle term are established.

Mathematics subject classification (2010): 34K11, 39A10, 39A99, 34C10, 34C15, 34N05. Keywords and phrases: oscillation criteria, fourth order, dynamic equations, time scales.

\section{REFERENCES}

[1] M. Bohner And A. Peterson, Dynamic Equations on Time Scales: An Introduction with Applications, Birkhäuser, Boston, 2001.

[2] M. Bohner AND T. S. HASSAN, Oscillation and boundedness of solutions to first and second order forced functional dynamic equations with mixed nonlinearities, Appl. Anal. Discrete Math., 3, 2 (2009), 242-252.

[3] L. ERBe, T. S. HASSAN AND A. PETERSON, Oscillation of second order neutral delay differential equations, Adv. Dyn. Syst. Appl., 3, 1 (2008), 53-71.

[4] L. Erbe, T. S. Hass An, A. Peterson ANd S. H. SAKer, Interval oscillation criteria for forced second-order nonlinear delay dynamic equations with oscillatory potential, Dyn. Contin. Discrete Impuls. Syst. Ser. A Math. Anal., 17, 4 (2010), 533-542

[5] S. R. Grace, R. P. Agarwal, M. Bohner and D. O'Regan, Oscillation of second-order strongly superlinear and strongly sublinear dynamic equations, Commun. Nonlinear Sci. Numer. Simul., 14, 8 (2009), 3463-3471.

[6] S. R. Grace, M. Bohner and R. P. Agarwal, On the oscillation of second order half linear dynamic equations, J. Difference Equ. Appl., 15, 5 (2009), 451-460.

[7] S. R. GRACE, On the oscillation of nth-order dynamic equations on time scale, Mediterr. J. Math., 10, 1 (2013), 147-156.

[8] S. R. GRACE AND T. S. HASSAN, Oscillation criteria for higher order nonlinear dynamic equations, Math. Nachr. 287, 14-15 (2014), 1659-1673.

[9] T. S. HASSAN, L. ERBE AND A. Peterson, Oscillation criteria for second order sublinear dynamic equations with damping term, J. Difference Equ. Appl., 17, 4 (2011), 505-523.

[10] T. S. HASSAN, Oscillation criteria for second-order nonlinear dynamic equations, Adv. Difference Equ., 2012, 2012:171, 13 pp.

[11] T. S. HASSAN, Asymptotic behavior of solutions of second order nonlinear dynamic equations, Dynam. Systems Appl. 23, 2-3 (2014), 179-187.

[12] S. HiLger, Analysis on measure chains - a unified approach to continuous and discrete calculus, Results Math., 18, 1-2 (1990), 18-56. 